\title{
Formatos e determinantes da participação social em agendas da Política Externa Brasileira ${ }^{1}$
}

\section{Forms and determinants of social participation in Brazilian Foreign Policy}

\author{
Melissa Elizabeth Pomeroy \\ Centro de Estudos e Articulação da Cooperação Sul-Sul \\ E-mail: melissapomeroy@gmail.com \\ Laura Trajber Waisbich \\ Centro de Estudos e Articulação da Cooperação Sul-Sul \\ E-mail: laura.waisbich@gmail.com
}

Resumo: No marco analítico que concebe a política externa brasileira (PEB) como política pública e, portanto, submetida a controles democráticos, e com base nos recentes estudos que evidenciam a pluralidade de atores e agendas e a complexificação do processo decisório em política externa, busca-se aqui analisar as iniciativas participativas existentes no marco da PEB e a qualidade democrática do diálogo entre Executivo e sociedade civil nas agendas de política externa. $\mathrm{O}$ trabalho se apoia nos avanços dos estudos sobre participação democrática e busca identificar similaridades e diferenças em formatos e dinâmicas das iniciativas de participação no âmbito da PEB, verificando assim a existência de tendências e determinantes. Para tanto, são analisadas iniciativas participativas em quatro âmbitos da política externa, quais sejam, negociações internacionais multilaterais comerciais, integração regional, cooperação sul-sul para o desenvolvimento e direitos humanos.

Palavras-Chave: Participação Social; Política Externa; Brasil; Políticas Públicas; Democratização.

\begin{abstract}
In close alignment with the analytical frameworks that conceive Brazilian Foreign Policy (BFP) as a public policy, hence subjected to democratic oversight, and drawing on the recent studies that highlight the plurality of actors and agendas and the increasing complexification of the decision-making process in foreign policy, this article intends to investigate participation initiatives in BFP and the democratic quality of state-society dialogue in foreign policy agendas. The present work is inspired by the developments in the study of democratic participation and seeks to identify similarities and differences in forms and dynamics of participation in BFP as to verify tendencies and determinants. This article analyses participation initiatives in four thematic areas of Brazilian foreign policy, namely multilateral

\footnotetext{
${ }^{1}$ Uma versão deste artigo foi apresentada durante o III Encontro Internacional Participação, Democracia e Políticas Públicas, em 2017. Agradecemos a Roberto Pires, Daniel Avelino e Ursula Peres pelos valiosos comentários feitos na ocasião.
} 
POMEROY, Melissa Elizabeth; WAISBICH, Laura Trajber. Formatos e determinantes da participação social em agendas da Política Externa Brasileira.

trade negotiations, regional integration, South-South cooperation for development and human rights.

Keywords: Social Pariticpation; Foreign Policy; Brazil; Public Policy; Democratization.

\section{Introdução}

Os processos brasileiros de democratização e abertura econômica ocorridos nas últimas três décadas favoreceram uma diversificação das agendas de política externa. A inserção político-econômica do país em um mundo globalizado, a diversificação de suas parcerias internacionais e o crescente protagonismo internacional do Brasil em uma série de agendas, âmbitos e temáticas fez com que a política externa brasileira (PEB) gerasse impactos distributivos internos, acentuando seu caráter competitivo (Lima, 2000) e sua politização (Lima, 2003; Milani \& Pinheiro, 2013). Cresceram, por conseguinte, pressões por reformas e abertura do principal órgão executor da política externa: o Ministério das Relações Exteriores (MRE ou Itamaraty) (Milani, 2011).

Este fenômeno, definido por alguns estudiosos como "democratização da política externa", é caracterizado por transformações em seu processo decisório em dois sentidos complementares e simultâneos: a horizontalização (aumento de atores estatais que passam a integrar o processo decisório) e a verticalização (maior abertura ao diálogo com atores nãogovernamentais) (França \& Sanchez, 2009). Este fenômeno pode ser visto em diversas agendas temáticas; do comércio exterior à participação em Missões de Paz da Organização das Nações Unidas (ONU), de migrações a negociações multilaterais setoriais, como as do clima.

Juntos, ambos os processos têm promovido relativa abertura do Itamaraty ao diálogo social, desafiando o tradicional "insulamento burocrático" sob o qual o órgão historicamente consolidou sua atuação (Cheibub 1985; Faria 2008; Belém Lopes 2010), mantendo-se a si mesmo e a PEB pouco permeáveis às dinâmicas participativas que se avolumaram no Brasil desde a década de 1980 nas diferentes políticas públicas, sobretudo nas sociais.

Revista Brasileira de Políticas Públicas e Internacionais, v.4, n.1, julho/2019, pp. 105-130. 
POMEROY, Melissa Elizabeth; WAISBICH, Laura Trajber. Formatos e determinantes da participação social em agendas da Política Externa Brasileira.

No entanto, apesar da falta de instituições participativas ${ }^{2}$ nos moldes mais tradicionais observados em outras políticas públicas (com conselhos e conferências estabelecidos em lei), esta progressiva abertura tem gerado uma miríade de diálogos de formatos e graus de formalização diversos; pontuais, ad hoc ou permanentes, que abarcam distintos aspectos da atuação diplomática brasileira. Dado esse ecossistema de formas de interação Estado-sociedade e considerado seu caráter globalmente não sistemático, a literatura avalia o marco contemporâneo do processo decisório em política externa como marcado por um "republicanismo mitigado" (Belém Lopes, 2014, pp.504) ou ainda por uma aproximação gradual, ainda que sem uma "institucionalização permanente" (Faria, 2015, pp.124).

Esta dinâmica no âmbito da PEB tem ocorrido paralelamente a significativas mudanças no âmbito doméstico. Por um lado, desde a redemocratização, o Brasil experimentou a institucionalização em escala de instituições participativas (Avritzer, 2012). Por outro, com o fim do período autoritário, a sociedade civil brasileira se descapsula e se fortalece, seja na forma de movimentos sociais ou organizações não-governamentais especializadas (Dagnino, 2002). Entidades brasileiras também se juntam, a partir do fim da década de 1990, à chamada "sociedade civil global" mobilizada nas mais distintas temáticas transfronteiriças. Assim, o espaço internacional passa a ser complementar à articulação de estratégias de contestação ou de incidência em políticas domésticas e globais.

Estes dois fatores, a democratização das políticas públicas brasileiras e o fortalecimento e internacionalização da sociedade civil, agregam elementos importantes à análise da abertura dos processos decisórios da PEB. Progressivamente, expande-se na academia, o conceito de política externa como política pública e sua caracterização como um contínuo das dinâmicas político-econômicas domésticas e, portanto, reflexo da disputa entre os atores e interesses presentes na sociedade que competem pelo acesso ao processo decisório (Pinheiro \& Milani, 2011).

Ecoando esta abordagem, a literatura específica passa a esmiuçar diversos aspectos dessa caracterização da PEB como política pública, tais como os novos arranjos institucionais

2 Por instituições participativas, entende-se a "série de formatos híbridos caracterizados pela presença de instituições com a participação da sociedade civil e de atores estatais" encarregadas da deliberação sobre políticas públicas (Avritzer 2007, pp. 443).

Revista Brasileira de Políticas Públicas e Internacionais, v.4, n.1, julho/2019, pp. 105-130. 
POMEROY, Melissa Elizabeth; WAISBICH, Laura Trajber. Formatos e determinantes da participação social em agendas da Política Externa Brasileira.

entre atores governamentais e as alterações e continuidades do papel tradicionalmente desempenhado pela burocracia diplomática brasileira. Emergem estudos sobre as competências constitucionais para atuar em distintas etapas do ciclo da política externa por parte do Executivo (Sanchez et al, 2006; França \& Sanchez, 2011) e do Legislativo (Lima \& Santos, 2001; Soares, 2005; Fares, 2005; Figueira, 2009), bem como análises sobre a internacionalização do Estado e ampliação das agendas da política externa (Milani \& Pinheiro 2013; Cason \& Power, 2009). Interessa-se, por fim, pelo novo papel de coordenador e articulador inter-burocrático do MRE (Faria, 2008; Faria, Nogueira \& Belém Lopes, 2012) nas diferentes agendas das relações exteriores do Brasil.

Entretanto, subsiste um longo caminho a ser perfilado no que tange ao estudo da participação social no contexto da democratização da PEB, objeto do presente trabalho. Questões centrais da literatura sobre democracias participativas e deliberativas, como a representatividade (Lavalle et al, 2006; Avritzer, 2007), a contribuição efetiva de instâncias participativas para o processo decisório das políticas públicas (Avritzer, 2011; Pires, 2011), o desenho institucional e a efetividade de instituições participativas (Avritzer, 2008) ou ainda as dinâmicas de ativismo institucional (Abers, Serafim \& Tatagiba, 2014), apenas começam a ser exploradas no âmbito da PEB (Pomeroy, 2016; Mesquita, 2016; Faria, 2017).

Assim, busca-se aqui analisar a qualidade democrática do diálogo entre Executivo e sociedade civil em temas de política externa. As questões centrais que se impõem são: como se dá o aprofundamento democrático na formulação da política externa? Em que medida, esse processo de democratização tem feito transparecer a pluralidade dos interesses em disputa e promovido uma construção democrática e inclusiva do conteúdo da política externa junto ao público doméstico?

Buscamos no artigo apontar e explicar similaridades e diferenças da participação da sociedade civil em distintas agendas de política externa, com o objetivo de identificar tendências e determinantes que contribuam para o entendimento sobre como se configuram as iniciativas participativas da política externa no Brasil pós-Constituição de 1988 até 2016.

Concretamente, analisaremos iniciativas de participação em quatro âmbitos da política externa, quais sejam, negociações internacionais multilaterais comerciais, integração regional,

Revista Brasileira de Políticas Públicas e Internacionais, v.4, n.1, julho/2019, pp. 105-130. 
POMEROY, Melissa Elizabeth; WAISBICH, Laura Trajber. Formatos e determinantes da participação social em agendas da Política Externa Brasileira.

cooperação sul-sul para o desenvolvimento e direitos humanos. Os âmbitos escolhidos perfazem áreas da PEB aonde existe significativa interação inter-burocrática (articulação e/ou conflito) ao longo do processo decisório e nos quais se identifica certo nível de mobilização de diferentes setores da sociedade civil. Dada a diversidade das temáticas e as particularidades político-institucionais de cada uma, este exercício comparado permite tecer comentários acerca das iniciativas participativas em política externa e dos arranjos que as sustentam, bem como dos desafios que estas trazem para o aprofundamento democrático da PEB.

$\mathrm{O}$ artigo analisa as iniciativas de participação a partir dos seguintes critérios - adaptados de Parés e Castella (2009):

(i) quem participa das iniciativas: extensão da participação ou qual o grau de abertura da iniciativa para um número suficientemente amplo de participantes; representatividade e diversidade dos participantes ou em que medida a iniciativa consegue incorporar representantes da diversidade da sociedade; e método de seleção, se é por meio de convite fechado a participantes específicos ou aberto à sociedade;

(ii) como se dá essa participação: metodologias utilizadas para organizar melhor o debate e proporcionar direito a voz a todos participantes; periodicidade contínua ou pontual/ ad hoc; e qualidade da informação proporcionada, entendendo esta como fundamental para formação de opiniões e decisões e, consequentemente, uma participação qualificada;

(iii) natureza de participação, traduzida em uma escala de menor a maior capacidade de incidência dos participantes: informativa, consultiva, vinculante, cogestão;

(iv) organização da participação: grau de formalização institucional ou em que medida a iniciativa participativa é formalizada e conta com regras que garantem clareza dos objetivos e formatos da participação; lócus institucional referente à entidade governamental responsável pela iniciativa; e origem da iniciativa - se foram iniciativas reivindicadas pela sociedade civil ou propostos pelo governo ${ }^{3}$.

De forma complementar, são adotadas ferramentas teóricas provenientes da Análise de Política Externa (APE) e da literatura sobre movimentos sociais, entendendo que a última

\footnotetext{
${ }^{3}$ Este último critério é proveniente de Gaventa (2006) que trabalha com a tipologia de espaços autogeridos, por convite ou fechados (em inglês: "claimed spaces", "invited spaces" e "closed spaces").
}

Revista Brasileira de Políticas Públicas e Internacionais, v.4, n.1, julho/2019, pp. 105-130. 
POMEROY, Melissa Elizabeth; WAISBICH, Laura Trajber. Formatos e determinantes da participação social em agendas da Política Externa Brasileira.

oferece uma série de ferramentas analíticas para o entendimento da atuação da sociedade civil, dimensão em geral relegada pela primeira, cujo foco central segue sendo o Estado e os atores governamentais.

Assim, por um lado, o campo da APE aporta subsídios para acessar os determinantes domésticos e externos que influenciam os processos decisórios da política externa. Aponta, em particular, a artificialidade da separação entre política externa e doméstica e comprova empiricamente que o processo decisório da PEB responde às disputas e interesses dos grupos domésticos assim como de oportunidades e constrangimentos presentes no âmbito internacional (Milner, 2007). A APE nesse sentindo contribui para a compreensão das dinâmicas que possibilitaram e/ ou motivaram - desde a perspectiva do Executivo - a abertura à participação de atores não-governamentais nos diferentes âmbitos selecionados.

Já o segundo bloco, contribui com aportes sobre as dinâmicas de mobilização social, incluso em sua vertente transnacional (Tarrow, 1998), para explicar - desde uma perspectiva dos agentes societários - a mobilização dos mesmos em pautas internacionais e de política externa, incluindo a relação entre as estruturas de oportunidades domésticas e internacionais. Segundo Tarrow (2005), os sistemas de normas doméstico e internacional condicionam os repertórios de política - contenciosa ou colaborativa - escolhidos pelos atores da sociedade civil . Entre estes repertórios, destaca-se, por exemplo, o "efeito bumerangue", entendido como a capacidade de atores domésticos da sociedade civil para aceder ao âmbito internacional com o objetivo de influenciar decisões domésticas (Keck \& Sikkink, 1998).

O presente estudo se apoia, na sistematização de dados existentes em fontes secundárias, quais sejam, os estudos sobre o processo decisório em agendas da política externa ${ }^{4}$. A análise é complementada com reflexões oriundas da observação participante em

\footnotetext{
${ }^{4}$ Importante salientar que nem todos os estudos revisitados abordam a questão da participação no processo decisório ou na deliberação sob o marco teórico da participação ou da deliberação democrática. No entanto, todos eles trazem informações relevantes sobre atores e dinâmicas participativas em voga nas últimas décadas em distintos processos decisórios no campo da PEB. Ainda, dado a escolha por trabalhar primordialmente com fontes secundárias, cada um dos casos apresentados discute de maneira distinta os critérios delineados acima, não havendo, portanto, equivalência na quantidade de informação e no nível de detalhamento para cada critério entre os casos.
}

Revista Brasileira de Políticas Públicas e Internacionais, v.4, n.1, julho/2019, pp. 105-130. 
POMEROY, Melissa Elizabeth; WAISBICH, Laura Trajber. Formatos e determinantes da participação social em agendas da Política Externa Brasileira.

alguns dos espaços analisados entre 2013 e 2016, nas agendas de cooperação Sul-Sul, de integração regional e direitos humanos.

Na próxima seção, apresentaremos os quatro casos. A terceira seção inclui uma breve discussão comparada sobre fatores, determinantes e dinâmicas da participação em política externa no Brasil contemporâneo. A seção final conclui o artigo e traz propostas para futuras agendas de pesquisa no tema da participação social na PEB.

\section{Participação em Questões de Política Externa: Quatro Casos}

As próximas subseções analisam as dinâmicas participativas nas quatro áreas de Política Externa selecionadas à luz dos critérios propostos.

\subsection{Negociações Internacionais Multilaterais Comerciais}

No caso da participação nas negociações multilaterais de comércio, a maior parte da literatura se centra nas preferências e formas de atuação de grupos de interesse do setor privado e organizações da sociedade civil, analisando as condições domésticas e externas para explicar posições e resultados das negociações de acordo com as preferências de cada grupo (Veiga, 2007; Carvalho, 2010; Santana, 2001; Oliveira \& Milani, 2012; Carvalho, 2003). Influenciadas pela teoria de jogos de dois níveis (Putnam, 1988), as produções analisam o processo decisório à luz de seus resultados, principalmente em dimensões como credibilidade, legitimidade e poder de barganha. Não obstante, proporcionam elementos para entender o formato de diálogo estabelecido entre atores não-governamentais, sobretudo o empresariado, e a burocracia diplomática.

Entre as iniciativas participativas analisadas pela literatura encontram-se: (i) no âmbito das negociações da Área de Livre Comércio das Américas (ALCA), a Seção Nacional de Coordenação dos Assuntos Relacionados à Área de Livre Comércio das Américas (Senalca) em 1996, coordenada pelo MRE e autorizada a convidar, para participar como observadores, entidades representativas do empresariado, de sindicatos e da sociedade civil organizada ${ }^{5}$

\footnotetext{
5 Apesar de sua atualidade, o caso da participação de atores sociais no Acordo UE-Mercosul parece ser pouco estudado. Destaca-se, entretanto, a partir de documentos primários, similaridade com a tendência geral exposta
}

Revista Brasileira de Políticas Públicas e Internacionais, v.4, n.1, julho/2019, pp. 105-130. 
POMEROY, Melissa Elizabeth; WAISBICH, Laura Trajber. Formatos e determinantes da participação social em agendas da Política Externa Brasileira.

(Oliveira \& Milani, 2012; Faria, 2017); (ii) o Grupo de Trabalho sobre Comércio Internacional de Mercadorias e de Serviços (GICI), criado por decreto em 1999 e sediado no MRE. O decreto não especificava critérios sobre a participação de representantes não-governamentais, mas o Grupo acabou convidando representantes do setor produtivo e dos trabalhadores (Carvalho, 2003); (iii) no âmbito das negociações Mercosul e UE, a Seção Nacional de Consulta sobre a União Europeia foi criada à luz da Senalca em 2001, porém com processos mais fechados à participação da sociedade civil organizada (Oliveira \& Milani, 2012); (iv) no âmbito das negociações da Rodada Doha e no bojo da reformulação do Ministério de Agricultura, Pecuária e Abastecimento (MAPA), a Câmara Temática de Negociações Agrícolas Internacionais, criada em 2003, na qual organizações representativas do agronegócio tinham assento permanente (Carvalho, 2010); (v) nas negociações da Alca e na OMC, representantes da Coalizão Empresarial Brasileira (CEB) integraram a delegação brasileira e acompanharam as negociações dos diplomatas em tempo real (Oliveira \& Milani, 2012).

Como principais características dessa participação destacam-se: (i) informalidade, baixa institucionalização e discricionariedade da burocracia diplomática respeito a abertura de canais de participação - em relação a quem convidar, quando convocar, sobre agendas e definição de formatos; (ii) escassas informações proporcionadas pela burocracia diplomática; (iii) carácter informativo ou consultivo das iniciativas; (iv) baixa representatividade dos participantes convidados pelo Executivo, com predominância do setor empresarial e produtivo; (v) a motivação em abrir os canais de participação centrada na busca por legitimidade de posições pré-estabelecidas pelas burocracias e não pela busca por consenso sobre a posição brasileira ou pressão por parte de atores não-governamentais (Veiga, 2007; Carvalho, 2003; Santana, 2001). Finalmente, ainda que atribuir a efetividade da participação no conteúdo final das negociações exija mais pesquisa, parece ser unânime na literatura sobre o tema a baixa capacidade de influência que esses canais de diálogo exerceram sobre as posições brasileiras (Veiga, 2007; Santana, 2001; Carvalho 2010).

nessa subseção. Por exemplo, a REBRIP (2017) denuncia a falta de transparência das negociações. Por outro lado, comunicados da Confederação Nacional das Indústrias (CNI) apontam para a regularidade do envio de missões empresariais que acompanham as Rodadas de negociação, realização de estudos e interlocução com negociadores (CNI 2017).

Revista Brasileira de Políticas Públicas e Internacionais, v.4, n.1, julho/2019, pp. 105-130. 
POMEROY, Melissa Elizabeth; WAISBICH, Laura Trajber. Formatos e determinantes da participação social em agendas da Política Externa Brasileira.

A respeito do caráter discricionário e informal, a produção acerca do tema, refletindo as primeiras iniciativas de diálogo na década de 1990, identifica que a assimetria de informações entre representantes diplomáticos e atores não-governamentais contribui para que o poder de agenda-setting se concentre no governo (Santana, 2001; Oliveira \& Milani, 2012). Nesse sentido, setores empresariais, movimentos sociais e sindicatos buscaram estratégias autônomas para superar a dependência de informações do governo. No caso dos atores da sociedade civil, seu histórico de articulação internacional contribuiu para que acessassem informações junto a redes transnacionais de movimentos e sindicatos (Santana, 2001). O setor empresarial, por sua vez, se organizou domesticamente para gerar conhecimento e expertise necessários para uma atuação mais informada junto ao governo (Carvalho, 2010).

Esse processo também gerou novas institucionalidades, como a criação da Coalizão Empresarial Brasileira (CEB), do Fórum Permanente de Negociações Agrícolas Internacionais, da Rede Brasileira pela Integração dos Povos (REBRIP). Estas contribuíram para maior expressão da diversidade de atores nas instâncias de diálogo, conformadas a partir de convites feitos pelo Itamaraty, sem utilização, entretanto, de critérios de representatividade (Santana, 2001; Carvalho, 2003; Oliveira \& Milani, 2012; Veiga, 2007). As produções também pontuam que os diálogos se estenderam para outros ministérios, como por exemplo para o MAPA, o Ministério de Desenvolvimento Agrário - MDA (hoje extinto), Ministério do Desenvolvimento, Indústria e Comércio - MDIC e Ministério do Meio Ambiente - MMA, impondo desafios à questão de coordenação por parte do MRE (Veiga, 2007; Carvalho, 2013).

\subsection{Integração Regional}

Ao tomar a integração regional como uma das áreas de análise, é importante esclarecer que diversos temas e setores apresentam interfaces regionais. Nesse sentido, pincelamos algumas características da participação da sociedade civil sob o prisma da integração a partir de dois âmbitos: (i) doméstico, através do Programa MERCOSUL Social Participativo (PMSP), coordenado até 2016 pela então Secretaria Geral da Presidência (SGPR) e que estabeleceu diálogo permanente entre governo e sociedade civil sobre os diversos temas da integração no MERCOSUL; (ii) regional e temático, através da Rede Especializada de Agricultura Familiar

Revista Brasileira de Políticas Públicas e Internacionais, v.4, n.1, julho/2019, pp. 105-130. 
POMEROY, Melissa Elizabeth; WAISBICH, Laura Trajber. Formatos e determinantes da participação social em agendas da Política Externa Brasileira.

(REAF), que configura uma participação diretamente no âmbito institucional do MERCOSUL. O primeiro foi selecionado por ser o principal espaço institucionalizado de debate participativo sobre integração regional no âmbito do Executivo, enquanto o segundo é reconhecido como um dos fóruns mais abertos à participação da sociedade civil no âmbito do MERCOSUL (Alemany \& Leandro, 2006).

O PMSP destaca-se por contar com institucionalização, representatividade e diversidade dos participantes. Instituído por decreto presidencial em 2008, o Programa contava um Conselho, reuniões periódicas e uma proposta de regulamento que previa composição e funcionamento. Representantes da sociedade civil, de setores variados ${ }^{6}$, podiam participar e encaminhar propostas para as Cúpulas Presidenciais do MERCOSUL (Mesquita, 2016).

O fato de o MERCOSUL contar com espaços formais de participação, e com uma Unidade de Participação Social, seguramente influenciou a necessidade de estabelecer um espaço doméstico de coordenação de posições da sociedade civil brasileira (Mesquita, 2012). Vale ressaltar também que a SGPR foi, até 2016, o órgão responsável pela participação social no Executivo Federal e, portanto, o acúmulo de experiência e conhecimento específico na matéria contribuiu para que o programa contasse com uma concepção de participação mais qualificada (Pomeroy, 2016).

A REAF, por sua vez, foi criada em 2004, congregando "organizações de referência" em agricultura familiar, como resultado da como confluência dos interesses do governo brasileiro e um grupo de movimentos sociais e sindicatos (Bülow \& Carvalho, 2012). Para o governo, particularmente MRE e o extinto MDA, a REAF conferiria coerência às interfaces doméstica e internacional da política externa. Domesticamente, por meio das políticas de apoio à agricultura familiar e, internacionalmente, por meio da apresentação de alternativas ao modelo de integração proposto no marco das negociações da ALCA. Para as organizações brasileiras mobilizadas para influenciar o processo de integração regional, a REAF representava uma oportunidade para fortalecer suas agendas e ampliar os espaços de influência (Bülow \& Carvalho, 2012). Além disso, o consenso existente sobre a necessidade de

\footnotetext{
${ }^{6}$ Mesquita (2016) registra, a partir de documentos proporcionados pela SGPR, a participação dos seguintes setores: Academia, Comunicação, Cooperativismo, Direitos Humanos, Educação/ Cultura, Empresarial, Fóruns e Redes, Igualdade Racial, Juventude, LGBT, Migração, Movimento Urbano, Mulheres, Sindical e Trabalho Rural.
}

Revista Brasileira de Políticas Públicas e Internacionais, v.4, n.1, julho/2019, pp. 105-130. 
POMEROY, Melissa Elizabeth; WAISBICH, Laura Trajber. Formatos e determinantes da participação social em agendas da Política Externa Brasileira.

envolvimento das sociedades no processo de integração regional contribuiu à abertura do MERCOSUL para a sociedade civil (Ramanzini Júnior \& Farias, 2015). Por outro lado, vale destacar que a missão institucional do MDA identificava a sociedade civil como ator central para a formulação de políticas públicas, já que sua criação visava "responder às demandas da sociedade e dos movimentos sociais por políticas de reforma agrária e desenvolvimento rural sustentável, com ênfase na agricultura familiar" (Brasil, s/d).

A breve análise de ambas iniciativas aponta para as seguintes características (i) alto grau de formalização institucional das experiências; (ii) elevado nível de representatividade e diversidade de participantes; (iii) continuidade dos espaços participativos; (iv) participação de natureza consultiva; (iv) influência, no formato final das experiências, da concepção sobre o papel da sociedade civil e da participação cidadã dos atores que promovem as iniciativas (SGPR e MDA) (v) confluência de motivações domésticas e internacionais para a criação dos espaços participativos.

\subsection{Cooperação Sul-Sul para o Desenvolvimento}

O processo decisório da cooperação sul-sul brasileira é marcado por sua descentralização. A Agência Brasileira de Cooperação (ABC), entidade subordinada ao MRE, tem responsabilidade legal para coordenar a cooperação técnica recebida e fornecida. A esse quadro, somam-se os ministérios e agências governamentais, responsáveis pela implementação da cooperação técnica e que também têm competências legais para atuar internacionalmente (Leite et al, 2014).

Tal descentralização resulta em possibilidades variadas para a participação da sociedade civil, dado que aumenta as interfaces de interlocução com as estruturas governamentais. Assim, é possível identificar ao menos três dinâmicas simultâneas de participação da sociedade civil nessa agenda: (i) participação em iniciativas governamentais; (ii) esforços autogeridos para a criação de espaços de debate e influência, e (iii) ação direta transnacional, por meio de redes de solidariedade e iniciativas de cooperação autogeridas (Pomeroy et al.,2016; Berrón \& Brant, 2015).

Revista Brasileira de Políticas Públicas e Internacionais, v.4, n.1, julho/2019, pp. 105-130. 
POMEROY, Melissa Elizabeth; WAISBICH, Laura Trajber. Formatos e determinantes da participação social em agendas da Política Externa Brasileira.

Uma tentativa inicial de identificação de iniciativas de participação promovidas pelo governo que abarcam as agendas da cooperação sul-sul, indicam que esses espaços costumam ser consultivos e apenas tangenciais ao tema da cooperação (Leite et al., 2014).

Já os projetos de cooperação específicos com participação da sociedade civil são escassos. Nesses poucos casos, o conhecimento especializado da sociedade civil, em geral, serve como ponto de partida para implementar projetos concebidos pelo governo (Santos, 2013).

Em alguns casos, a sociedade civil apresentou propostas para implementar seus próprios projetos e angariou apoio do governo. Como exemplo, o Projeto Bancos comunitários de sementes crioulas para a agricultura familiar, com participação da SGPR, do Instituto Brasileiro de Análises Sociais e Econômicas, Movimento Camponês Popular e Movimento de Mulheres Camponesas (Suyama \& Pomeroy, 2015). Ou ainda, como o caso da ONG Viva Rio, que chegou inicialmente ao Haiti a convite da MINUSTAH e expandiu sua atuação implementando projetos autonomamente e em parceria com instituições brasileiras (Waisbich \& Pomeroy, 2014). Destaca-se, ainda, a participação do extinto Conselho Nacional de Segurança Alimentar e Nutricional (CONSEA), por meio de trocas com a sociedade civil dos países participantes, no programa Purchase from Africans for Africa (PAA AFRICA), coordenado pela extinta Coordenação-Geral de Ações Internacionais de Combate à Fome (CG-Fome) (Beghin, 2014). Nesta iniciativa, um maior protagonismo da sociedade civil pode ser explicado pela existência de consenso, por parte dos atores governamentais liderando o PAA AFRICA, sobre a participação social como fator de êxito na implementação doméstica do Programa de Aquisição de Alimentos (no qual se inspira o PAA AFRICA) (Leite et al, 2015).

No âmbito da cooperação, a participação social encontra maior terreno em espaços autogeridos, que buscam fortalecer a capacidade da sociedade civil em monitorar e influenciar as práticas de cooperação oficiais (Ciommo \& Amorim, 2015), ou em iniciativas de cooperação solidária ou ativista (Marcolini, 2014; Berrón \& Brant 2015). No caso dos espaços que buscam debater e influenciar o papel do Brasil na cooperação internacional, os participantes incluem acadêmicos e think-tanks, assim como organizações da sociedade civil com amplo histórico de atividade transnacional em temas da governança multilateral (Ciommo \& Amorim, 2015).

Revista Brasileira de Políticas Públicas e Internacionais, v.4, n.1, julho/2019, pp. 105-130. 
POMEROY, Melissa Elizabeth; WAISBICH, Laura Trajber. Formatos e determinantes da participação social em agendas da Política Externa Brasileira.

Já às iniciativas de cooperação solidária se apoiam nos laços políticos transnacionais construídos entre organizações de países em desenvolvimento, e encontram-se diretamente ligadas a agendas de resistência ao modelo de desenvolvimento hegemônico e às prescrições neoliberais das Instituições Financeiras Internacionais, das décadas de 1980 e 90 (Pomeroy et al, 2016). As atividades desenvolvidas no marco dessa cooperação ativista variam num contínuo entre colaboração e atividades contenciosas, centradas em troca de conhecimento, apoio à mobilização política e coordenação de agendas de resistência internacional (Berrón \& Brant, 2015). O caso da mobilização entre movimentos brasileiros, moçambicanos e japoneses em torno da Campanha não ao ProSAVANA é um exemplo emblemático dessa agenda de política contenciosa. A existência de laços anteriores e uma agenda política comum facilitaram a coordenação dos movimentos que juntos desenvolveram uma série de atividades, incluindo conferências internacionais, cartas aos três governos, visitas para troca de experiência e uma agenda de influência para pressionar os governos por maior transparência do projeto (Aguiar \& Pacheco, 2016).

Assim, no âmbito da cooperação sul-sul, é possível observar uma maior predominância de experiências autogeridas e de iniciativa da própria sociedade civil, nas quais a articulação e presença internacional pré-existente das organizações é um fator determinante. A participação em iniciativas governamentais, por meio da implementação de projetos de cooperação sul-sul, é mais tímida e necessita de maior pesquisa empírica para um melhor entendimento das interfaces e de como são feitos e negociados os convites e a natureza da participação.

\subsection{Direitos Humanos}

A política externa brasileira de direitos humanos (PEBDH) pode ser pensada a partir de três eixos: (i) implementação no Brasil de tratados, decisões e recomendações internacionais; (ii) participação do Brasil em órgãos internacionais (regionais ou universais); (iii) saliência do tema nas relações bilaterais do país. Nos três observa-se tentativas por parte de organizações da sociedade civil de participar e influenciar o processo decisório. Sua mobilização possui forte viés jurídico-normativo, amparado pela Constituição de 1988, que prevê a prevalência dos direitos humanos na condução das relações internacionais do Brasil (Art. 4, II). Como em

Revista Brasileira de Políticas Públicas e Internacionais, v.4, n.1, julho/2019, pp. 105-130. 
POMEROY, Melissa Elizabeth; WAISBICH, Laura Trajber. Formatos e determinantes da participação social em agendas da Política Externa Brasileira.

outras temáticas, a participação da sociedade civil é facilitada e garantida em paralelo pelo sistema internacional por meio de canais próprios e relativamente formalizados ${ }^{7}$ (Lindgren Alves, 2001).

A participação social nesta temática cresceu em tandem com a redemocratização do país e com sua adesão aos principais instrumentos internacionais na matéria. Parte deste processo se deu no marco da chamada "década social das ONU", que contou com ativa participação do Estado e da sociedade civil brasileiros, por vezes de forma coordenada e outras de maneira autônoma (Lindgren Alves, 2001).

Nas últimas décadas, a tônica do diálogo Estado-sociedade variou entre a colaboração e o conflito, com interações que vão da fiscalização e denúncia (por exemplo de votos e posicionamentos), ao diálogo "por convite", mediação social e coexecução de políticas e serviços (Silva, 2016), com prevalência das duas primeiras. Ademais, dado as muitas instâncias internacionais das quais o Brasil participa (tanto no Sistema Interamericano de Direitos Humanos - SIDH quanto no âmbito da ONU), as dinâmicas de participação possuem distintos padrões de diálogo e graus de formalização. Entre os canais formalizados inclui-se a participação no âmbito da agenda social e de direitos humanos do MERCOSUL, no marco do PMSP, mencionado anteriormente. Nas demais subagendas, a literatura aponta para um panorama no qual a participação ocorre de modo pouco formalizado, pontual e ad hoc (por meio de canais formados para uma negociação ou de uma conferência que tendem a se extinguir findado o evento), respondendo a necessidades do Itamaraty e sem intenção de garantir cogestão nas decisões tomadas. Aponta também para as resistências da parte do Estado de prover os grupos de interesse com informações substantivas que auxiliem no diálogo e na interação (Silva, 2016; Nader \& Waisbich, 2015).

Outro elemento abordado é a interação da PEBDH com as políticas domésticas de direitos humanos e com suas instituições participativas, como o Conselho Nacional de Direitos Humanos. A literatura aponta para o diálogo e coordenação entre a Divisão de Direitos Humanos do Itamaraty, a então Secretaria de Direitos Humanos (SDH) e o Ministério da

\footnotetext{
${ }^{7}$ A sociedade civil tem direito à voz no $\mathrm{CDH}$ da ONU e tomam parte de contenciosos em cortes e órgãos quasejurídicos internacionais contra o Estado, seja como vítimas ou representantes de vítimas.
}

Revista Brasileira de Políticas Públicas e Internacionais, v.4, n.1, julho/2019, pp. 105-130. 
POMEROY, Melissa Elizabeth; WAISBICH, Laura Trajber. Formatos e determinantes da participação social em agendas da Política Externa Brasileira.

Justiça em certos âmbitos, como, por exemplo, nas respostas a casos contra o Brasil no SIDH, bem como no marco da elaboração de relatórios aos órgãos de tratados da ONU e dos planos nacionais de direitos humanos (Milani, 2011). No entanto, esse diálogo é inconstante e varia de acordo com a agenda. No caso das instituições participativas, observa-se baixa mobilização das mesmas na construção das posições internacionais do Brasil, ainda que haja indícios de uma maior interação direta destes conselhos com o sistema internacional, como canal de denúncia ou utilizando da "jurisprudência internacional" como instrumento na barganha interna com outros órgãos estatais. É visível ainda os efeitos das mútuas interações entre as dinâmicas de horizontalização e verticalização na PEBDH em subagendas como a de "empresas e direitos humanos"; dada à natureza transversal do tema e em resposta à pressão da própria sociedade civil para que a formulação dos posicionamentos externos do país seja melhor articulada com atores domésticos, sejam eles governamentais ou não.

Nos anos mais recentes, observam-se também dinâmicas complementares às formas ad hoc dominantes. Um exemplo, impulsionado por uma demanda vinda da sociedade civil, do Comitê Brasileiro de Direitos Humanos e Política Externa - CBDHPE, foi a criação de audiências públicas anuais no Congresso sobre a PEBDH e das videoconferências periódicas entre entidades da sociedade civil, o MRE, a SDH e a Procuradoria Federal dos Direitos do Cidadão - PFDC (órgão do Ministério Público Federal) para discutir posições internacionais do Brasil. Estas interações promovidas pelo Comitê simbolizam uma "primeira tentativa de utilização de um espaço institucional permanente para a interlocução entre Estado e sociedade civil na área da PEBDH” (Silva, 2016, pp.21) e uma novidade importante no padrão de participação, apontando para a maior saliência de interações facilitadas por arranjos híbridos, composto por órgãos de Estado e por entidades da sociedade civil. As videoconferências também dialogam com formas nascentes de participação virtual.

No caso da PEBDH, reconhece-se uma gradual abertura à participação, sobretudo no Itamaraty, que, todavia, coexiste com dinâmicas de politização e tensão (Milani, 2011) e com frequentes críticas, por parte da sociedade civil, à baixa transparência do órgão e a pouca frequência e efetividade das interações (Silva, 2016; Martins, 2016, Waisbich et al., 2017). Salienta-se também, a baixa diversidade e capilaridade no território nacional dos atores sociais

Revista Brasileira de Políticas Públicas e Internacionais, v.4, n.1, julho/2019, pp. 105-130. 
POMEROY, Melissa Elizabeth; WAISBICH, Laura Trajber. Formatos e determinantes da participação social em agendas da Política Externa Brasileira.

que participam das interações, ainda dependente do ativismo e protagonismo de organizações profissionalizadas e concentradas no eixo Rio de Janeiro-São Paulo-Brasília.

Assim, em linhas gerais, é possível caracterizar a participação na PEBDH como constituída de uma miríade de iniciativas autogeridas e crescentes interfaces - nem sempre formalmente institucionalizadas - com atores estatais, para além do MRE. A participação tem sido historicamente impulsionada pela existência de oportunidades e recursos no âmbito dos sistemas internacionais de direitos humanos, abrangendo sub-temáticas distintas de direitos humanos. Nacionalmente, o diálogo com os formuladores de política externa também reflete as múltiplas dimensões da $\mathrm{PEBDH}$, mas segue limitado a ONGs profissionalizadas da região Sudeste do país.

\section{Dinâmicas e Fatores Determinantes da Participação na PEB}

Apesar da diversidade dos quatro casos discutidos, os mesmos nos permitem traçar reflexões mais sistêmicas sobre dinâmicas e determinantes da participação na PEB.

Primeiramente, atenta-se para a multiplicidade de canais de participação na PEB, com graus variados de formalização. Apesar da discricionariedade na abertura das iniciativas e sua natureza frequentemente ad hoc, aquelas formalizadas por lei ou decreto administrativo têm ganhado saliência em quase todas as temáticas. Observa-se a existência simultânea de espaços de participação criados pela sociedade civil, aonde predominam articulações de incidência para influência ou contestação, e de espaços "por convite", cuja seleção de participantes é discricionária, e sua natureza/finalidade é informativa ou consultiva. É necessário atentar ainda para o fato de alguns dos espaços "por convite" terem tido sua origem em inciativas da sociedade civil, progressivamente incorporadas pelas burocracias.

Prevalece, entre as iniciativas analisadas, o caráter consultivo, informativo e não vinculante dos canais de participação da sociedade civil na PEB abertos pelos órgãos estatais. Nos quatro casos, identificam-se similaridades com relação à escassez e à assimetria de informações para a participação e falta de metodologias estruturadas para balizar a interação. Com relação à diversidade, representatividade e extensão da participação, as iniciativas analisadas possuem em geral, baixa representatividade de atores sociais, pouca diversidade

Revista Brasileira de Políticas Públicas e Internacionais, v.4, n.1, julho/2019, pp. 105-130. 
POMEROY, Melissa Elizabeth; WAISBICH, Laura Trajber. Formatos e determinantes da participação social em agendas da Política Externa Brasileira.

geográfica e capilaridade no território nacional e faltam critérios de representatividade para participantes, com entraves à ampliação da participação a um universo mais amplo da sociedade civil brasileira. Os principais interlocutores são organizações profissionalizadas com capacidade de interlocução com a burocracia diplomática e conhecimento técnico nas diferentes temáticas. De fato, a criação de novas institucionalidades no âmbito da sociedade civil e do setor privado no caso das negociações comerciais, assim como a mobilização para a criação de redes de intercâmbios e debate no âmbito da cooperação sul-sul, indicam a relevância da construção de capacidades para a participação. Ainda, a própria atuação internacional da sociedade civil, seja entre homólogos ou no âmbito das organizações internacionais, contribui para sua capacidade de interlocução.

A respeito dos determinantes da abertura à participação, identificam-se diversos fatores que têm sua origem no âmbito internacional; como resposta à recomendações ou determinações internacionais com relação à necessidade de estabelecer processos participativos domésticos, a busca por legitimidade de posições pré-estabelecidas pelas burocracias, e a necessidade de coordenar posições naqueles casos em que existem mecanismos de participação no âmbito de instituições multilaterais, como no caso do MERCOSUL.

Observam-se também evidências do impacto positivo de uma maior horizontalização do processo decisório em temas de política externa, com a progressiva e crescente entrada de novos atores governamentais, na abertura de novas estruturas de oportunidade políticas para a mobilização dos atores não-governamentais na agenda. A coordenação de agendas da PEB junto a outros órgãos governamentais traz consigo, para a arena da política externa, as dinâmicas de relação entre Executivo e sociedade civil existentes no âmbito de distintas políticas setoriais, incluindo a experiência e a concepção de participação social dos demais órgãos, bem como os canais institucionais formais ou informais para diálogo social existentes no desenho das políticas domésticas. Tal aspecto evidencia a complementariedade dos processos de horizontalização e verticalização do processo decisório em política externa. Percebe-se incluso, em alguns casos, a aposta estratégica dos atores não-estatais na ampliação do diálogo interburocrático e no fortalecimento da posição de outros atores governamentais vis-

Revista Brasileira de Políticas Públicas e Internacionais, v.4, n.1, julho/2019, pp. 105-130. 
POMEROY, Melissa Elizabeth; WAISBICH, Laura Trajber. Formatos e determinantes da participação social em agendas da Política Externa Brasileira.

à-vis o MRE para a criação de mais e melhores canais para a participação social e influência neste mesmo processo decisório.

Por fim, de maneira agregada, os casos revelam, por um lado, que a pluralização de atores governamentais com capacidade de agência no âmbito da PEB e a abertura de canais de participação social de maneira descentralizada promovem mudanças significativas na capacidade de coordenação da agenda por parte do MRE. Por outro, faz-se, todavia, necessário um maior debate sobre diretrizes claras e transparentes sobre como e em quais momentos do ciclo da política deve dar-se a participação, quais formatos adotar e quais funções e papeis poderia desempenhar.

Ainda que o MRE tenha investido em ferramentas de "diplomacia pública" (Faria, 2017), o entendimento vigente do órgão acerca de transparência e diálogo social tem pouca aderência aos critérios normativos propostos pelas teorias de participação. Dada essa dissonância, e apesar do aumento nas iniciativas do Itamaraty neste âmbito (como o progressivo uso das mídias sociais, criação do Blog Diplomacia Pública e o plano de Dados Abertos), não cessaram de crescer demandas por maior transparência e previsibilidade da PEB, por exemplo por meio da publicação de um Livro Branco da Política Externa e pela criação de um órgão institucionalizado permanente de participação na PEB, no modelo de um fórum consultivo ou um conselho nacional (Pinheiro \& Milani, 2015). No entanto, apesar do aumento do debate público a esse respeito (incluso no contexto eleitoral com menções explícitas ao tema da participação social em política externa durantes as eleições presidenciais de 2014) as perspectivas atuais de criação tanto do Livro Branco quanto de um órgão participativo formal são quase nulas. $\mathrm{O}$ fato de ambos instrumentos terem sido ventilados nos últimos anos, e não terem saído do papel até hoje, alerta para os persistentes desafios para consolidação democrática no âmbito da PEB.

\section{Conclusão}

O presente trabalho buscou contribuir com reflexões acerca dos desafios a serem considerados no processo de abertura e participação social em política externa. Ao sistematizar estudos em quatro áreas temáticas distintas da atuação internacional do Brasil agregam-se

Revista Brasileira de Políticas Públicas e Internacionais, v.4, n.1, julho/2019, pp. 105-130. 
POMEROY, Melissa Elizabeth; WAISBICH, Laura Trajber. Formatos e determinantes da participação social em agendas da Política Externa Brasileira.

evidências importantes para um maior entendimento sobre o exercício do controle vertical entre Estado e sociedade e de seus arranjos e arcabouços institucionais.

O trabalho permite ainda ampliar as áreas de contato entre estudiosos no âmbito da análise de política externa e no campo das políticas públicas, dado que o debate sobre participação no Brasil, raramente considera os âmbitos da política externa e vice-versa. Acredita-se que o crescente foco no estudo da democratização da PEB por parte dos analistas de política externa tem muito a se beneficiar dos aportes vindos da teoria participativa, ampliando seu entendimento do processo de democratização, de seus efeitos e de seus limites. Por outro lado, para os estudiosos da participação, o campo da política externa permite testar hipóteses consolidadas em uma política pública cujos efeitos distributivos são menos evidentes e cujo grau de mobilização social é tradicionalmente mais baixo, apesar de certamente em expansão.

De forma sistemática, ainda que não exaustiva, entre as principais características da participação levantadas ao longo deste trabalho destacam-se: (i) informalidade, baixa institucionalização e discricionariedade da burocracia diplomática a respeito da abertura de canais de participação - em relação a quem convidar, quando convocar, sobre agendas e definição de formatos e metodologias de consulta; (ii) escassas informações proporcionadas pela burocracia diplomática para apoiar a participação; (iii) caráter informativo ou consultivo das iniciativas; (iv) baixa representatividade e diversidade dos participantes.

Os determinantes da abertura dos órgãos públicos, e sobretudo do MRE, ao diálogo e à participação social na PEB são dependente de três fatores principais: (i) da existência de uma coalizão ao redor de uma determinada temática que reúna setores da sociedade civil com histórico de atuação internacional ou capacidades específicas para dialogar com burocracias altamente especializadas; (ii) da participação dos demais atores governamentais, para além do MRE, no processo decisório e de sua concepção e práxis sobre participação; e (iii) oportunidades no âmbito internacional que incentivem, induzam ou causem algum tipo de constrangimento para iniciativas ou decisões não participativas por parte do Estado brasileiro.

Destaca-se também a pouca saliência na literatura de análises acerca da qualidade da deliberação, nos casos aonde os mecanismos permitem algum nível de coconstrução de

Revista Brasileira de Políticas Públicas e Internacionais, v.4, n.1, julho/2019, pp. 105-130. 
POMEROY, Melissa Elizabeth; WAISBICH, Laura Trajber. Formatos e determinantes da participação social em agendas da Política Externa Brasileira.

posicionamentos, e do grau de influência dos espaços de participação nos processos decisórios e nos produtos da deliberação. Esta última, no entanto, se apresenta como uma agenda de pesquisa futura já apontada por alguns como a nova fronteira a ser explorada por aqueles que se interessam pelo tema da democratização da PEB (Farias \& Ramanzini Júnior, 2015). Em conjunção com esse ponto, um mais aprofundado exercício de tipificação das iniciativas participativas ou interfaces socioestatais existentes nas distintas agendas de política externa segundo suas finalidades, tal como desenvolvido por Pires e Vaz (2014) em seu estudo com gestores federais acerca de um rol de políticas públicas domésticas, pode avançar esse debate no sentido de trazer à tona não apenas os formatos, mas também seus papeis e contribuições para a produção desta política.

Outros campos que se abrem para futuras investigações que aprofundem o diálogo entre os estudiosos de política externa e a produção sobre instituições participativas, seriam mapeamentos e análises mais extensivos de iniciativas de participação no âmbito da política externa e pesquisas sobre diversidade e representatividade dos participantes. Abrem-se igualmente novas fronteiras de estudos sobre o papel dos burocratas do nível da rua ou de médio escalão e de suas interações com a sociedade civil na implementação da política externa brasileira.

Por fim, no médio prazo seria importante investir em novos estudos empíricos que tragam dados de como a participação social tem ocorrido desde 2016, desde o impeachment de Dilma Rousseff, e mais recentemente sob o governo de Jair Bolsonaro, dadas as mudanças de prioridades na PEB bem como os câmbios institucionais no MRE e em outros ministérios, com a extinção de pastas e a reorganização de competências.

\section{Referências}

Abers, R. N.; Serafim, L.; Tatagiba, L. (2014) Repertórios de interação estado-sociedade em um estado heterogêneo: a experiência na Era Lula. Dados: Revista de Ciências Sociais, 57 (2), 25-357.

Revista Brasileira de Políticas Públicas e Internacionais, v.4, n.1, julho/2019, pp. 105-130. 
POMEROY, Melissa Elizabeth; WAISBICH, Laura Trajber. Formatos e determinantes da participação social em agendas da Política Externa Brasileira.

Aguiar, D.; Pacheco, M.E (2016) A Cooperação Sul-Sul dos Povos do Brasil e de Moçambique: Memória da Resistência ao ProSavana e Análise Crítica de seu Plano Diretor. Rio de Janeiro: FASE.

Alemany, C.; Leandro, B. (2006) Análisis y propuestas para la participación ciudadana en el MERCOSUR. Montevideo: Friedrich Ebert Stiftung.

Avritzer, L. (2007) Sociedade Civil, Instituições Participativas e Representação: Da Autorização à Legitimidade da Ação. Dados 50(3), 443-464.

(2008) Instituições participativas e desenho institucional: algumas considerações sobre a variação da participação no Brasil democrático. Opinião Pública, 14(1), 43-64.

(2011) A qualidade da democracia e a questão da efetividade da participação: mapeando o debate. In Pires, R. Efetividade das instituições participativas no Brasil: estratégias de avaliação. (pp. 13-15) Brasília: Instituto de Pesquisa Econômica Aplicada.

(2012) Conferências nacionais: ampliando e redefinindo os padrões de participação

social no Brasil. Texto para discussão 1739, Brasília: Instituto de Pesquisa Econômica Aplicada.

. (2014) O que está em jogo no segundo mandato de Dilma Rousseff? Recuperado a partir de https://diplomatique.org.br/o-que-esta-em-jogo-no-segundo-mandato-de -dilma-rousseff/

Beghin, N. (2015) A Cooperação brasileira para o desenvolvimento internacional na área de segurança alimentar e nutricional: avanços e desafios; onde estamos e para onde vamos? Brasília: INESC

Belém Lopes, D. (2010) Da Razão de Estado Ao Republicanismo Mitigado. Tese de doutorado. Universidade do Estado do Rio de Janeiro.

(2014) Da razão de estado ao republicanismo mitigado: uma narrativa Faoriana sobre a produção da Política Externa Brasileira. Dados, 57(2), 481-516.

Berrón, G; Brant, M. Expertise, Disputa Política ou Solidariedade? Variações sobre o Engajamento da Sociedade Civil Brasileira na Cooperação Sul-Sul. In: Ramazini Júnior, H; Ayerbe, L F (Eds.), Política externa brasileira, cooperação sul-sul e negociações internacionais. (pp 251-284) São Paulo: Cultura Acadêmica.

Brasil. (s/d). Ministério do Desenvolvimento Agrário. Recuperado a partir de http://www.mda.gov.br/sitemda/pagina/hist\%C3\%B3rico\#sthash.Xxm2Kmsy.dpuf

Revista Brasileira de Políticas Públicas e Internacionais, v.4, n.1, julho/2019, pp. 105-130. 
POMEROY, Melissa Elizabeth; WAISBICH, Laura Trajber. Formatos e determinantes da participação social em agendas da Política Externa Brasileira.

Bulow, M; Carvalho, P.D. (2012) Entre o nacional e o transnacional. O caso das organizações da agricultura familiar no Mercosul. In: GOHN, M. G; BRINGUEL, B. M. Movimentos Sociais na Era Global. (pp 229-246) Petropólis: Vozes.

Cason, J W.; Power, T. J. (2009) Presidentialization, Pluralization, and the Rollback of Itamaraty: Explaining Change in Brazilian Foreign Policy Making in the Cardoso-Lula Era. International Political Science Review 30(2), 117-140.

Carvalho, M.I. (2003) Estruturas domésticas e grupos de interesse: a formação da posição brasileira para Seattle. Contexto Internacional, 25(2), 363-401

(2010) Condicionantes internacionais e domésticos: o Brasil e o G-20 nas negociações agrícolas da rodada Doha. Dados, 53(2), 405-445

Cheibub, Z. B. (1985) Diplomacia e construção institucional: o Itamaraty em uma perspectiva histórica. Dados, 28(1), 113-131

Ciommo, M.; Amorim, A. (2015) Brazil as an International Actor: Drivers for Development Cooperation. Development Initiatives Briefing

Confederação Nacional das Indústrias (2017) Indústria brasileira quer agilizar acordo comercial com União Europeia. Recuperado a partir de https://noticias.portaldaindustria.com.br/ noticias/internacional/industria-brasileira-quer-agilizar-acordo-comercial-com-uniao-europeia/

Dagnino, Evelina (2002) Sociedade civil e espaços públicos no Brasil. São Paulo, Paz e Terra/Unicamp

Fares, S T. (2005) Democratização da Política Externa Brasileira: O papel do Legislativo. Dissertação de Pós-Graduação, Brasília: Universidade de Brasília

Faria, C. A. P. (2008) Opinião pública e política externa: Insulamento, politização e reforma na produção da política exterior do Brasil. Revista Brasileira de Política Internacional, 51(2), 8097.

Faria, C. A. P.; Nogueira, J. L. M.; Belém Lopes, D. (2012) Coordenação intragovernamental para a implementação da política externa brasileira: o caso do Fórum IBAS. Dados, 55(1), 175220.

Faria, V.D. (2017) Política Externa e participação social: trajetória e perspectivas. Cadernos de Política Exterior, 2(4), 133-140.

Farias, R.S; Ramanzini Júnior, H. (2015) Reviewing horizontalization: the challenge of analysis in Brazilian foreign policy. Revista Brasileira de Política Internacional 58(2), 5-22.

Revista Brasileira de Políticas Públicas e Internacionais, v.4, n.1, julho/2019, pp. 105-130. 
POMEROY, Melissa Elizabeth; WAISBICH, Laura Trajber. Formatos e determinantes da participação social em agendas da Política Externa Brasileira.

Figueira, A. C. (2009). Processo Decisório em Política Externa. São Paulo: Universidade de São Paulo.

França, C; Sanchez, M. R. (2009) A horizontalização da política externa brasileira. Valor Econômico, Opinião, 24 abril. . (2010) A Inserção Internacional do Poder Executivo Nacional Brasileiro. Análises e Propostas, Friedrich Ebert Stiftung.

Gaventa, J. (2006) Finding the spaces for change: a power analysis. IDS Bulletin 37, 23-33.

Keck, M. E., \& Sikkink, K. (1998). Activists beyond Borders. Advocacy Networks in International Politics. Ithaca: Cornell University Press.

Lavalle, A. G., Houtzager, P., \& Castello, G. (2006). Representação, Pluralização da Representação e Sociedade Civil. Lua Nova (57), 49-103.

Leite, I. C., Suyama, B., Waisbich, L., \& Pomeroy, M. (2014). Brazil's Engagement in International Development Cooperation: the state of the debate. Brighton: Institute of Development Studies.

Leite, I., Pomeroy, M., \& Suyama, B. (2013). Africa-Brazil co-operation in social protection: Drivers, lessons and shifts in the engagement of the Brazilian Ministry of Social Development. Helsinki: UNU-WIDER.

Lima, M. R. (2000). Instituições Democráticas e Política Exterior. Contexto Internacional, 22(2), 265-303.

. (2003) O Legislativo e a Política Externa. In: Rebelo, A; Fernandes, L; Cardim, C.H. (eds.). Política Externa do Brasil para o Século XXI. Brasília: Câmara dos Deputados, Coordenação de Publicações, Série Ação Parlamentar. 41-52.

. (2010) Tradição e Inovação na Política Externa Brasileira. Working Paper, Rio de Janeiro: Plataforma Democrática.

Lima, M. R; Santos, F. (2001) O Congresso e a Política de Comércio Exterior. Lua Nova, (52), 121-149.

Lindgren Alves, J A. (2001) Relações internacionais e temas sociais: a década das conferências. Brasília: Funag/IBRI.

Revista Brasileira de Políticas Públicas e Internacionais, v.4, n.1, julho/2019, pp. 105-130. 
POMEROY, Melissa Elizabeth; WAISBICH, Laura Trajber. Formatos e determinantes da participação social em agendas da Política Externa Brasileira.

Marcolini, M. D. (2014). La participación de las organizaciones de la sociedad civil en la Cooperación Sur-Sur de Brasil: buscando un enfoque integral de participación. Revista Iberoamericana de Estudios de Desarrollo, 3(2), 130-147.

Martins, M. (2016) Advocacy e Influência na Política Externa Brasileira em Direitos Humanos: The Advocacy Coalition Framework como referencial teórico para pesquisa empírica. Revista Brasileira de Políticas Públicas e Internacionais, 1(2), 91-110.

Mesquita, L. R. (2012). Sociedade civil e Política Externa Brasileira: os espaços participativos na PEB contemporânea. OIKOS, 11(2), 281-301.

(2016) Representação, democracia e política externa. A participação social como indutora de mudanças na política externa? Tese (doutorado), Belo Horizonte: Universidade Federal de Minas Gerais, Faculdade de Filosofia e Ciências Humanas.

Milani, C. (2011) Atores e agendas no campo da política externa brasileira de direitos humanos. In: Pinheiro, L; Milani, C. Política externa brasileira a política das práticas e as práticas da política. Rio de Janeiro: FGV, 33-70.

. (2015) Brazil's Human Rights Foreign Policy: Domestic Politics and International Implications. Politikon: South African Journal of Political Studies, 42(1) 67-9,

Milani, C., \& Pinheiro, L. (2013). Política Externa Brasileira: Os Desafios de sua Caracterização como Política Pública. Contexto Internacional, 11-41.

Milner, H. (2007). Interests, institutions, and information: domestic politics and international relations. Princeton: Princeton University Press.

Nader, L., Waisbich, L. (2015) The long march towards the democratization of Brazilian foreign policy. In: van Lindert, T.; van Troost, L. (eds.). Shifting Power and Human Rights Diplomacy Brazil, Amsterdam: Amnesty International, 87-95.

Oliveira, I. T., \& Milani, C. (2012). Atores Não Estatais e Trade Policy-Making no Brasil: Análise dos Interesses e das Estratégias da CEB e da REBRIP. DADOS, 55(2), p. 367-401.

Parés, M; Castellà C. (2009) Una propuesta de criterios de calidad democrática para evaluar los procesos participativos. In: Parés, Marc. Participación y Calidad Democrática: Evaluando las nuevas formas de democracia participativa, Barcelona: Ariel, 241-266

Pinheiro, L., \& Milani, C. (2011). Política externa brasileira a política das práticas e as práticas da política. Rio de Janeiro: FGV Editoria.

Revista Brasileira de Políticas Públicas e Internacionais, v.4, n.1, julho/2019, pp. 105-130. 
POMEROY, Melissa Elizabeth; WAISBICH, Laura Trajber. Formatos e determinantes da participação social em agendas da Política Externa Brasileira.

Pires, R. C. (2011). Efetividade da Instituições Participativa no Brasil: Estratégias de Avaliação. Brasília: IPEA.

Pomeroy, Melissa. (2016) Participación Ciudadana y Política Exterior. La confluencia entre actuación doméstica y transnacional de la sociedad civil brasileña. Tese (doutorado), Barcelona: Universitat Autònoma de Barcelona, Institut de Govern i Polítiques Públiques.

Pires, R R. C.; Vaz, A C. N. (2014). Para além da participação: interfaces socioestatais no governo federal. Lua Nova, 93, 61-91.

Putman, R. (1988). Diplomacy and domestic politics: the logic of two-level games. International Organization, 42 (3), 427-460.

Ramanzini Júnior, H; Farias, R. S. (2015) Missão impossível? Mercosul, participação social e política externa no Brasil. Pensamento Próprio, 40, 355-275.

REBRIP (2016) Proposta de Acordo com a União Europeia é ataque aos direitos e ao futuro do país! Acesso em 21 de maio de 2019. Recuperado a partir de http://www.rebrip.org.br/ noticias/proposta-de-acordo-com-a-uniao-europeia-e-ataque-aos-direitos-e-ao-futuro-do-pai$3288 /$

Sanchez, M. R., Silva, E., Cardoso, E., \& Spécie, P. (2006). Política Externa como Política Pública: uma análise pela regulamentação constitucional brasileira (1967-1988). Revista de Sociologia Política, 125-143.

Santana, H. (2001). Grupos de Interesse e a Política Externa para a ALCA. Contexto Internacional, 23(1), 167-196.

Santos, T.C.S.S (2013). Entre o norte e o sul: um estudo sobre o papel das organizações da sociedade civil brasileira na cooperação internacional para o desenvolvimento. Tese (doutorado). Universidade Federal da Bahia, Escola de Administração da Universidade Federal da Bahia, Salvador.

Schmitz, G. d. (2014). A Sociedade civil brasileira e a cooperação sul-sul para o desenvolvimento: estudo de caso do Viva Rio no Haiti. Boletim de Economia e Política Internacional, 16, 75-90.

Silva, D. C. (2016) A incidência das ONGs na agenda da Política Externa Brasileira de Direitos Humanos: O Caso do Comitê Brasileiro de Direitos Humanos e Política Externa. Artigo apresentado no 10o Encontro da ABCP, Belo Horizonte - MG, 30 de agosto a 02 de setembro.

Revista Brasileira de Políticas Públicas e Internacionais, v.4, n.1, julho/2019, pp. 105-130. 
POMEROY, Melissa Elizabeth; WAISBICH, Laura Trajber. Formatos e determinantes da participação social em agendas da Política Externa Brasileira.

Suyama, B., Pomeroy, M. (2015). Supporting 'Autonomy and Resistance': the BrazilMozambique-South Africa native seed bank project (No. Case Study 4). Brighton: Institute of Development Studies.

Soares, C.L.B. (2005) O processo legislativo e a aprovação de acordos internacionais assinados pelo Brasil. Brasília: Instituto Rio Branco.

Tarrow, Sidney. (1998) Power in Movement: Social Movements and Contentious Politics. Cambridge: Cambridge University Press.

Tarrow, S. (2005). The New Transnational Activism. Cambridge: Cambridge University Press. Veiga, P. d. (2007). Trade policy-making in Brazil: Changing patterns in state-civil society relationship. In M. Halle, \& R. Wolfe, Process matters: Sustainable Development and Domestic Trade Transparency (pp. 143-183). Winnipeg: IISD.

Waisbich, L. T., Pomeroy, M. (2014). Haiti - Um laboratório de engajamento multisetorial. São Paulo: Observatório Brasil e o Sul, Articulação Sul.

Waisbich, L. T., Cetra, R.; Marchezini, J. The Transparency Frontier in Brazilian Foreign Policy. Contexto internacional, 39(1), 179-200.

Revista Brasileira de Políticas Públicas e Internacionais, v.4, n.1, julho/2019, pp. 105-130. 